\title{
JUREMA: culto, religião e espaço público
}

\author{
Zuleica Dantas Pereira Campos* \\ Clelia Moreira Pinto Joron ${ }^{* *}$
}

\section{Resumo}

Objetivamos neste trabalho compreender as construções simbólicas de que se utilizam os seguidores da Jurema (religião afro-ameríndia) na sua busca de legitimação. Para tanto, abordamos a invenção dessa religiosidade, que se construiu tomando como base simbólica as representações étnico-religiosas ameríndia e africana da região Nordeste do Brasil; e, dessa forma, compreender como se organiza o processo de popularização, de institucionalização e de inserção no espaço público da prática da Jurema na Região Metropolitana do Recife. Trabalhamos com a ideia de que sua principal reivindicação é a da legitimação como religião autônoma. E é nesse sentido que consideramos o culto da Jurema, seja ele praticado entre grupos indígenas da região Nordeste, seja praticado no espaço urbano da Região Metropolitana do Recife, como um processo contínuo de transformação. Frente a um mundo fluidificado e globalmente conectado, a Jurema reivindica também sua legitimação no campo da sociedade nacional.

Palavras-chave: Religiões afro-ameríndias. Identidade. Negros. Índios. Legitimidade.

\section{JUREMA: worship, religion and public space}

\begin{abstract}
In this work, we aim to comprehend the symbolic constructions used by the followers of Jurema (Afro-Amerindian religion) in their search for legitimation. In order to make an approach to this religiosity, which is built on a symbolic basis, the ethnic-religious representations of Amerindian and Africans of the Northeast region of Brazil; and in this way to understand how the process of popularization, institutionalization and insertion into the public space of Jurema practice is organized in the Metropolitan Region of Recife. We work with the idea that its main claim is a legitimation as an autonomous religion. In addition, we consider the worship of Jurema, whether practiced
\end{abstract}

\footnotetext{
* Professora titular do Programa de Pós-Graduação em Ciências da Religião da Universidade Católica de Pernambuco - UNICAP.

** Mestre em Antropologia pela Universidade Federal de Pernambuco - UFPE.
} 
among indigenous groups in the Northeast region, or practiced in the urban space of the Metropolitan Region of Recife, as a continuous process of transformation. Faced with a fluidized and globally connected world, Jurema also claims its legitimacy in the field of national society.

Key-words: Afro-amerindian religions. Identity. Blacks. Indians. Legitimacy.

\section{JUREMA: el culto, la religión y el espacio público}

\section{Resumen}

Este trabajo tiene por objetivo entender las construcciones simbólicas que utilizan los seguidores de Jurema (religión afro-amerindia) en su búsqueda de legitimidad. Por lo tanto, tiene la intención de acercarse a la invención de esta religiosidad, que se construyó utilizando como base simbólica, las representaciones étnicas y religiosas de origen africano y amerindio del noreste de Brasil; y así comprender cómo se organiza el proceso de popularización de la institucionalización y la integración en el espacio público de la práctica de la Jurema la Región Metropolitana de Recife. Trabajamos con la idea de que la reivindicación principal es el de la legitimidad como la religión autónoma. Y es en este sentido que consideramos el culto de Jurema, ya sea practicado entre grupos indígenas en la región noreste, o practicado en el espacio urbano de la Región Metropolitana de Recife, como un proceso continuo de transformación. Frente a un mundo fluidizado y conectado globalmente, la Jurema también reivindica su legitimidad en el campo de la sociedad nacional.

Palabras clave: Religiones afro-amerindias. Identidad. Negros. Indios. Legitimidad.

\section{Introdução}

A Jurema faz parte de um complexo cultural que inclui os Estados do Rio Grande do Norte, Paraíba, Pernambuco, Alagoas e Sergipe. Também denominada Catimbó, Macumba e Toré e é caracterizada pela incorporação de entidades denominadas Mestres e Caboclos, e pelo uso ritual da bebida e do fumo. Configura-se, assim, como uma prática ritual predominantemente nordestina, e também é encontrada no chamado Candomblé de Caboclo, no Estado da Bahia (PINTO, 1995).

É considerada por aqueles que a utilizam como mensageira de um efeito mágico curativo. Possui as seguintes características: transe mediúnico - configurado pela presença de entidades espirituais -, ingestão de bebidas e limpeza pelo fumo. O panteão mágico religioso da Jurema é composto por Reis, Rainhas, Príncipes, Princesas, Caboclos e Caboclas. Essas entidades habitam o juremá ou cidade da Jurema, terra dos "encantados" ou espíritos ali radicados em diversos reinos, sendo os mais conhecidos o de Vajucá, Tigre, Canindé, Urubá, Juremal, Josafá e o Reino do Fundo do Mar (CASCUDO, 1988). 
O culto à jurema é sincretizado e se organiza por meio de um conjunto de símbolos emprestados do catolicismo popular e de traços culturais e religiosos africanos e indígenas. Apropriados e de novo relacionados, esses símbolos são utilizados de forma inovadora e original (PINTO, 1995).

A cidade da Jurema é materializada no quarto sagrado em que ficam os símbolos representativos das entidades. Lá se encontram os cálices e vasilhas de louça - branca ou transparente -, representando os príncipes e princesas. O fumo de rolo, a aguardente e os cachimbos correspondem aos Mestres. O matiricó, cachimbo fabricado com a raiz da Jurema, e o vinho branco são associados aos Caboclos e Caboclas. Nas categorias de Reis e Rainhas não existe equivalente simbólico no quarto sagrado. Algumas vezes, a figura do dirigente da casa é associada a essas categorias, ou é interpretada como entidades que, devido ao seu nível de espiritualidade, não podem ter correspondência a um objeto material. Em outros momentos, Reis e Rainhas são categorias que correspondem a alguns Mestres, como o Mestre Carlos, considerado um rei da Jurema (PINTO, 1995).

$\mathrm{O}$ quarto dedicado às entidades da Jurema está sempre em local de pouco destaque no terreiro e tem dimensões menores em relação ao quarto (Peji) dedicado aos orixás. Em algumas Juremas é oferecido sacrifício de pombos ou pintos e, às vezes, bichos de quatro pés também são ofertados às entidades. Porém, na Jurema considerada como tradicional o sacrifício não é uma obrigação, havendo mesmo certa preferência pelos alimentos associados à ideia de natureza, coerentes com a representação do índio - entre os juremeiros - de pureza e de inocência. Utiliza-se então, entre outros, frutas, mel, sucos, vinho (resultado da mistura de ervas e raízes em infusão), inhame, carimã (papa feita de mandioca).

Roberto Motta (1977; 1988; 1999) e Maria do Carmo Brandão (1985), num amplo trabalho de campo dedicado à observação das práticas religiosas entre os afro-recifenses, distinguem a diversidade daquelas práticas rituais e suas singularidades na Região Metropolitana do Recife. Pioneiros desse campo de estudos, nesta cidade, dão conta da especificidade dessas práticas, distinguindo quatro práticas religiosas afro-pernambucanas: o Catimbó Jurema, o Xangô tradicional, a Umbanda Branca e o Xangô Umbandizado. O Catimbó Jurema, que corresponde ao culto dos Mestres e Caboclos, é considerado pelos autores como religião de caráter periférico, por estar enraizada em áreas rurais do Nordeste, especialmente em antigos aldeamentos indígenas.

Observa-se, ainda, a ausência de uma rigidez no que toca aos códigos rituais, flexibilidade que permite uma personalização do culto ao livre-arbítrio de cada juremeiro. A jurema tem a imagem de um caleidoscópio, tendo como base um 
suporte de cores determinadas, e a composição desses elementos adquire forma própria a cada movimento provocado.

Para compreender as construções simbólicas feitas pelos seguidores da Jurema, na sua busca de legitimação, utilizamo-nos metodologicamente das sensibilidades desvendadas por Merleau-Ponty (1964). O autor considera que o indivíduo não é o único a ter o controle da produção da realidade. $\mathrm{O}$ sujeito (interior) e o que o cerca (exterior) existem enquanto dois sistemas interdependentes e imprevisíveis. Nesse caso, a percepção serve como modo de repercussão que mantém uma correlação entre o observador (eu) e o observado (mundo exterior). "Meu corpo", como afirma Merleau-Ponty, "é um objeto sensível a todos e repercute em todos os sons, vibra de todas as cores" (1964, p. 273).

Associamos ainda nosso pensamento à ideia desenvolvida por Gilles Deleuze e Felix Guattari (Milles Plateaux) de "indivíduo múltiplo, plural e transpassado pelas subjetividades sociais, em constante movimento". Nessa obra, Deleuze e Guattari desenvolvem o conceito de "pluralidade em movimento", de "horizontalidade fluida, liquida" de que o indivíduo faz parte. Ele se insere numa realidade subjetiva em constante movimento (DELEUZE; GUATTARI, 1980).

Atentamos ainda para o aspecto simbólico da Jurema, deidade telúrica, do tipo vegetal, que repousa no imaginário índio/negro do Nordeste brasileiro. Entendemos a Jurema como o "Sacral Naturel" como nos apresenta Maffesoli (2017). A Jurema é energia natural de um solo primitivo, o "Élan Vital" de Bergson, impulso e pulsão de vida que permite a continuidade e percepção do tempo real e mítico. A "sensibilite ecosophique" que "pensa e vive de maneira holística o relacionismo, unindo o individuo, a comunidade e o território" (MAFFESOLI, 2017, p. 219).

Assim, pretendemos neste trabalho abordar a construção dessa religiosidade que se construiu tomando como base simbólica as representações étnico-religiosa - ameríndia e africana - da região Nordeste do Brasil. Procuramos compreender como se organiza esse processo de popularização e de institucionalização, cada vez maior, da prática da Jurema, na Região Metropolitana do Recife, reivindicando e lutando para se inserir no espaço público, e legitimar-se como religião.

Habermas (2014) entende a esfera pública como ambiente de comunicação de múltiplos sujeitos da sociedade civil e suas relações com as instituições políticas do Estado. Nesse sentido, é um conceito complexo. É o lugar onde os assuntos públicos são discutidos pelos atores públicos e privados. É nessa dimensão que se forma opinião. Esta atua como uma ação proveniente da sociedade civil, no sentido de influenciar as decisões do sistema político. Deste modo, a esfera pública 
apresenta-se como processo de busca social, coletiva, institucional e, portanto, dialógica, objetivando o bem comum.

Pretendemos aqui trabalhar não com o conceito de esfera pública, mas de espaço público, entendido como a dimensão da sociedade civil que emerge com o Estado secular republicano. Esse espaço público não se configura plenamente como uma "esfera pública burguesa" tal qual Habermas (2014) discute e conceitua. O espaço público é lugar de discussão, de crítica. É um elemento articulador. São lugares criados para validar e legitimar a vontade do público.

\section{A Jurema na Região Metropolitana do Recife}

Gonçalves Fernandes, ao escrever "Xangôs no Nordeste", em 1937, faz referência ao que chamou de uma nova modalidade da religiosidade afropernambucana, que a denominou de "Xangô de Caboclo ou Centro de Caboclo do Batuque". Nesses Centros, ainda em número reduzido, existia a influência do elemento ameríndio. As entidades cultuadas eram: Jesus Cristo, chamado Caboclo Bom, e os santos João Evangelista e João Batista.

Os orixás ganharam novas denominações, um exemplo é o Orixá Xangô, que passou a ser chamado de Xangô de Caboclo. Foram incluídos entidades como a Sereia do mar, o culto a Exu e vários encantados. As oferendas consistiam em jerimum cozido com feijão e mel de abelha, canela e casca de Jurema. Fernandes ainda relata que os instrumentos musicais são diferentes, assim como a liturgia, e o uso mais frequente de palavras portuguesas.

René Ribeiro, em "Cultos Afro-Brasileiros do Recife” (1952), faz referência à prática do Catimbó - em Recife - no início do século XX. Eram Centros modestos, caracterizados pela "afiliação flutuante", centrada na figura de um:

Sacerdote mágico-adivinho. Eram centros de catimbó, e de caboclos onde o sincretismo religioso parece ter avançado mais, e em que parecem ter se transformado as antigas 'Casas de Angola' (RIBEIRO, 1952, p. 37).

José Jorge Carvalho (1987) faz alusão às práticas da Jurema e dos Xangôs tradicionais, em Pernambuco, e suas transformações por volta da década de 1950 . Ao que parece, para o autor, tratava-se de religiões ou cultos distintos porém:

Ainda outro processo de mudança que, suponho, começou também nos anos cinquenta, foi a aproximação cada vez maior entre os cultos de jurema e o xangô. A princípio, parecia que as casas de jurema começaram a introduzir toques de xangô, principalmente aos estilos xambá; igualmente, casas de xangô 
menos ortodoxas começaram a introduzir o culto da jurema. Essa síntese entre xangô e jurema foi crescendo com o tempo, a ponto de que, hoje em dia, existe pouquíssimas casas de xangô que não têm também, ainda que separados dos cultos aos orixás, toques de jurema (CARVALHO, 1987, p. 16-17).

Para o autor, a penetração da jurema estaria em relação direta com a ortodoxia do terreiro. E ainda acrescenta: "Resumindo, o xangô atualmente é forçado a existir com a Jurema, enquanto existem ainda centenas de casas dedicadas exclusivamente aos espíritos, sem trabalhar com o modelo de culto aos orixás" (CARVALHO, 1987, p. 17).

Motta (1999), ao distinguir a Jurema do Xangô, ressalta como diferença a simplificação sacramental e informalidade na organização eclesiástica, bastante rígidas no Xangô Ortodoxo. Existe uma forte presença de traços indígenas, emprego do ritual da fumaça de tabaco e da bebida denominada Jurema.

Para Motta (1999, p. 19), nos últimos anos vêm sendo acrescentados ao culto "conjuntos axiológicos procedentes do Rio de Janeiro", e de outras regiões. Dessa forma, a presença de Exus e Pombagira (Exus femininos) são resultados dessa migração. As categorias estariam divididas em Mestre, Caboclos e Exus (masculinos e femininos).

O trabalho de Pinto (1995), ao analisar o culto à Jurema nos terreiros de Xangô, apreende três formas ritualísticas de praticar a jurema. A Jurema de roda ou batida, aberta ao público, em que todos os juremeiros podem participar. São utilizados três tambores e maracás. A segunda modalidade é a Jurema de mesa. O ritual se aproxima mais das práticas espíritas kardecistas, em que os médiuns sentam-se em torno da mesa e fazem consultas curativas. Essa modalidade pode ser praticada de forma totalmente privada, ou seja, fechada ao público, surgindo daí outra prática descrita pela autora como Jurema de chão, considerado por alguns devotos como trabalhos voltados para a esquerda. A terceira categoria seria a Jurema de mata. A prática ritual é realizada na mata e se recorre a entidades ligadas a esta.

Neste trabalho, a autora percebe que existe uma necessidade de separação entre o mundo dos Orixás e o mundo dos encantados da Jurema, nos espaços físicos e rituais, priorizando os quartos dedicados aos orixás tanto nos terreiros de xangô quanto nos terreiros de Umbanda. Entre os praticantes do xangô, "a Jurema é colocada como suporte, vindo em segundo plano, e atendendo a questões que os orixás, devido a sua superioridade, negam-se ou demoram a atender" (PINTO,1995, p. 169). A Jurema é um reconhecimento, a religião é a dos orixás. Já na Umbanda, as práticas da Jurema são entendidas como parte da religião. 
De acordo com Pinto (1995), tudo levava à compreensão de que a Jurema sempre esteve presente nos terreiros de Xangôs do Recife. Uma vez que os estudiosos, do início do século XX, detiveram-se em estudar as práticas rituais ortodoxas ou tradicionais, fica difícil precisar como se estabeleceu de fato essa conexão.

Rodrigues (2014) ressalta que: "Embora grande parte dos juremeiros sejam, também, candomblecistas e/ou umbandistas, essas religiosidades não se misturam nos espaços físicos dos terreiros, mas se tocam na positividade dos corpos" (2014, p. 85). Para a autora, há uma complementaridade entre candomblecistas, umbandistas e juremeiros garantida pela "positividade barroca" do devir juremeiro, que conseguiu converter a política em religião.

Daí, podemos aludir pelos estudos dos autores que Jurema e Xangô coexistiram desde o início dos estudos realizados pelos antropólogos, embora não se precise quando aconteceu essa conexão.

Nos últimos anos, observa-se uma evidente visibilidade nas representações das manifestações étnico-religiosas (africana e ameríndia) na Região Metropolitana do Recife. Essas mudanças apontam para uma necessidade de redistribuição dos espaços de prática religiosa entre essas duas categorias, e de uma redefinição da importância e da distinção entre os dois grupos como identidade religiosa e forte reivindicação por uma emancipação vinda da parte dos juremeiros.

Figura 1 - Juremeira cachimbando nas matas do antigo quilombo de Catucá.

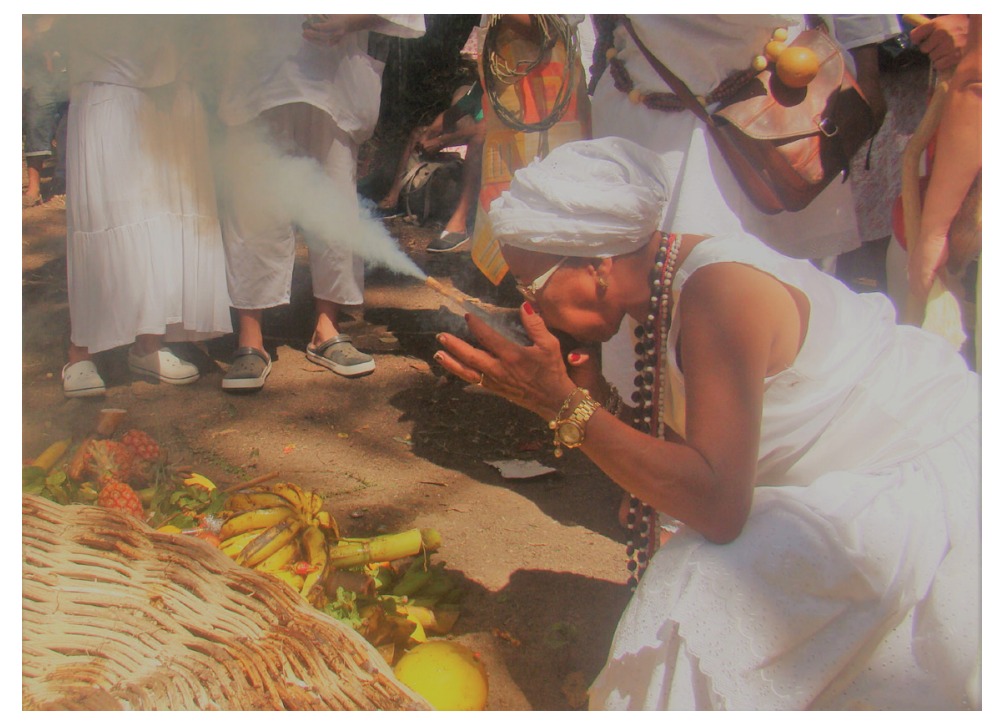

Fonte: Arquivo pessoal de Zuleica Dantas Pereira Campos. 
Destarte, sempre considerada como parente distante, a jurema deve sua sobrevivência graças à aliança estabelecida com as casas de Candomblé e de Umbanda. Apesar de sua imagem entre os afrodescendentes colocá-la em segundo plano, frente ao culto dos orixás, sua prática sempre existiu, mesmo se sua visibilidade foi ofuscada. Essa convivência sempre foi possível e sua presença e prática nunca ignoradas. Não parece que podemos falar de uma invisibilidade da Jurema, mesmo que sua presença eclipsada e incômoda tenha sido, por muito tempo, relegada a um quartinho nos fundos das casas de culto, sendo utilizada principalmente nos trabalhos de "baixo espiritismo", nas limpezas pelo fumo e nos conflitos ligados à marginalidade.

Pierre Livet (2010) não vê uma oposição entre visível e invisível. Apropriando-se do "shème du chiasme" desenvolvido por Merleau-Ponty para analisar a gênese do social e seus aspectos afetivos, Livet mostra, em sua análise, que a articulação entre o ("dehors") de fora, e o ("dedans") de dentro, se faz com a articulação do invisível (espírito) e do visível (coisas).

Merleau Ponty (1964) utiliza a noção do chiasma que poderíamos definir como a dupla face de uma pele invisível. Ao mesmo tempo em que nos coloca em contato, ela nos separa do eu interior e do eu exterior: "chiasme mon corps - les choses realisés par le dedoublement de mon corps en dedans et dehors..." (PONTY, 1964, p. 311). Ela também nos separa e nos conecta ao exterior, ao mundo das coisas e de seu próprio desdobramento: "et le dedoublement des choses leurs dedans et leurs dehors" (IDEM, p. 311-12). O mundo interior releva tudo que está ligado aos sentidos (ver, ouvir, tocar, sentir), que ele chama de mundo sensível, e está intimamente imbricado ao mundo das coisas, ao exterior, numa perpétua relação de atração e de repulsão.

O "chiasme" refere-se então ao shéme de um espaço de articulação entre o que está fora e o que está dentro, o real e o virtual. Como explica Livet (2010), a articulação entre o invisível e o visível. É nesse espaço de atrações e repulsões que tudo se toca e se separa, que tudo se funde e se individualiza em atualizações variadas e sucessivas. O shéme diz respeito também ao institucional, à relação e projeção com o outro, instituinte e instituído, comunicação intersubjetiva e simbólica. Na combinação de todos esses ingredientes se constrói o social de uma parte nas "interações virtuais e não apenas atuais, e de outra parte afetivas e emocionais", e não por meio unicamente das normas e dos valores (LIVET, 2010, p. 263).

É nesse sentido que compreendemos as relações sociais existentes no microcosmo religioso da Jurema. Nós a entendemos como espaços comunicacionais 
imbricados de vários aspectos. É construída a partir de uma interação emocional, simbólica e institucionalizante. Uma cumplicidade, uma conivência entre dois universos religiosos distintos que se autossustentam, cada um dando ao outro visibilidade ou invisibilidade para poder existir: "Il n'est donc pas non plus dans un lieu caché, Il est présent dans le visible, et invisible dans le visible précisément parce que voyant" (LIVET, 2010, p. 263) ("Ele não está num canto escondido, ele está presente no visível e invisível neste visível porque é visto").

A Jurema reivindica hoje seu estatuto de religião, sua autonomia como prática religiosa legítima, sua emancipação como religiosidade independente. Nessa busca de existência, ela percorre em paralelo os mesmos caminhos que a religiosidade afrodescendente na luta pelo seu reconhecimento na sociedade civil.

Figura 2 - Busca de autonomia por parte dos juremeiros.

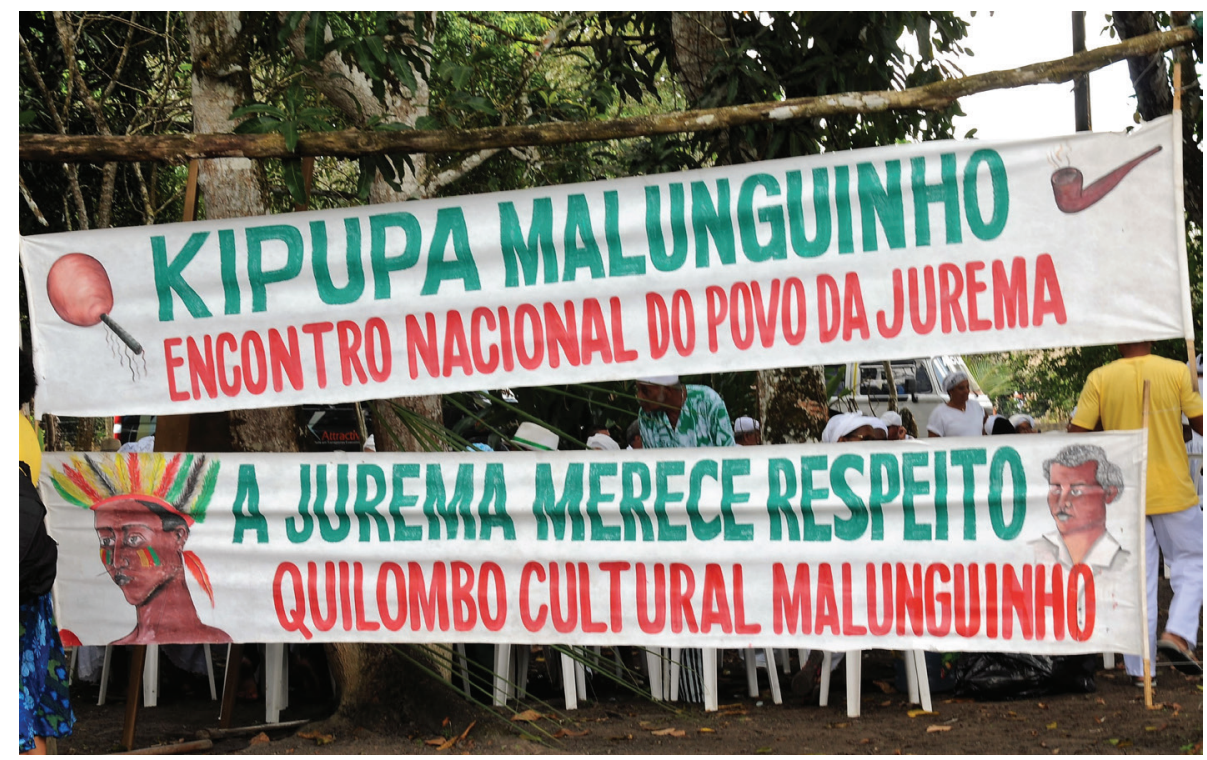

Fonte: Arquivo pessoal de Zuleica Dantas Pereira Campos.

\section{Jurema e espaço público}

Nos últimos trinta anos, o movimento político que valoriza a negritude e seus símbolos culturais vem tomando espaço, desenvolvendo diversas formas de intervenção e de atuação junto ao espaço público. Entre esses marcadores de singularidades, as religiões afro-brasileiras desempenham um papel importante. No entanto, apesar de a relação entre religiões afro-brasileiras e identidade negra não 
ser necessariamente obrigatória, essa vinculação vem sendo utilizada pelo Estado por meio das políticas de promoção da igualdade racial, favorecendo a inserção dessas religiões na cena pública.

Esse processo está fortemente marcado na memória desde os finais da década de 1980, momento em que o Movimento Negro Unificado se organiza no Estado de Pernambuco, de forma mais efetiva, e vai aos terreiros em busca de sua ancestralidade. Com esse processo político, as transformações no campo da cultura, da economia, da sociedade levaram os terreiros de Xangô, em Pernambuco, a repensar suas práticas, seus rituais, suas indumentárias, entrando em sintonia com os acontecimentos do mundo afro-religioso brasileiro.

Por conta da percepção de uma relação estreita entre religião e identidade, os movimentos sociais negros passam a incluir, sistematicamente, em sua agenda, a reivindicação por políticas públicas de proteção e promoção das chamadas religiões negras e de outros segmentos considerados excluídos. Essa visão aparece de modo bastante claro no Relatório Final da I Conferência Nacional de Promoção de Igualdade Racial, no item religiões de matriz africana. ${ }^{1} \mathrm{O}$ documento apresenta a sua visão sobre a orientação política que deve presidir a relação do Estado com as referidas religiões. Diz o texto:

A política abrange a garantia de respeito e a legitimidade social das sacerdotisas, sacerdotes, pajés e xamãs, por meio do direito assegurado de acesso aos espaços públicos, fóruns e participação em cerimônias ecumênicas; a proposição de uma legislação que defina e puna atos discriminatórios relativos à intolerância étnico-religiosa; políticas públicas de resgate e preservação do patrimônio cultural e material e de resguardo da religiosidade afrodescendente e da espiritualidade indígena; e ações que assegurem a regularização e o tombamento dos espaços ocupados pelas comunidades de terreiro, além do respeito à liberdade de expressão das crenças de matrizes africanas, indígenas, de ciganos, muçulmanos e judeus, garantindo a utilização das áreas tradicionais e o uso de objetos sagrados em todo e qualquer lugar (BRASIL, 2005, p. 105-106) (grifos dos autores).

Temos aqui uma declaração de princípios sobre as religiões e o seu papel na sociedade brasileira. Em primeiro lugar, pretende-se garantir o direito constitucional de líderes religiosos afrodescendentes e indígenas de se inserirem na esfera pública.

É uma declaração de princípios sobre as religiões afro-brasileiras e indígenas e seu papel na sociedade brasileira. O texto também afirma a amplitude da sua

Realizada em Brasília, em julho de 2005. 
contribuição, uma vez que influenciaram a própria formação da identidade nacional. Mais ainda, o texto fala de legitimidade, de combate à repressão. Também busca incluir no seu discurso outras minorias religiosas. Todas são vistas como ameaçadas pela sociedade englobante, daí a presença, no mesmo texto, de uma injunção recorrente para que o Estado assuma a proteção dessas religiões e do seu patrimônio. Nesse sentido, demandam-se ações voltadas para a preservação do patrimônio - cultural, material e socioambiental - das religiões.

É ancorado nesse contexto sociopolítico que, em 2007, um grupo de estudos realizado no ambiente do Arquivo Público Estadual Jordão Emereciano, na cidade de Recife - PE criaram o Quilombo Cultural Malunguinho - Histórico e Divino. As práticas desenvolvidas pelo grupo tiveram início no ano anterior, por intermédio de seminários em escolas públicas, cuja temática principal estava centrada nas religiões afro-brasileiras e indígenas, cultura negra e intolerância religiosa. Ao término do seminário aconteceu o I Kipupa Malunguinho. Os principais líderes do QCM são Alexandre L'Omi L'Odò e Sandro de Jucá (RODRIGUES, 2014, p. 109).

O Kipupa Malunguinho é um acontecimento anual, realizado no mês de setembro. O evento ocorre em terras do antigo Quilombo do Catucá, na área do antigo Engenho Pitanga II, zona da mata de Pernambuco, especificamente onde hoje é a cidade de Abreu e Lima.

Figura 3 - Kipupa Malunguinho 2015.

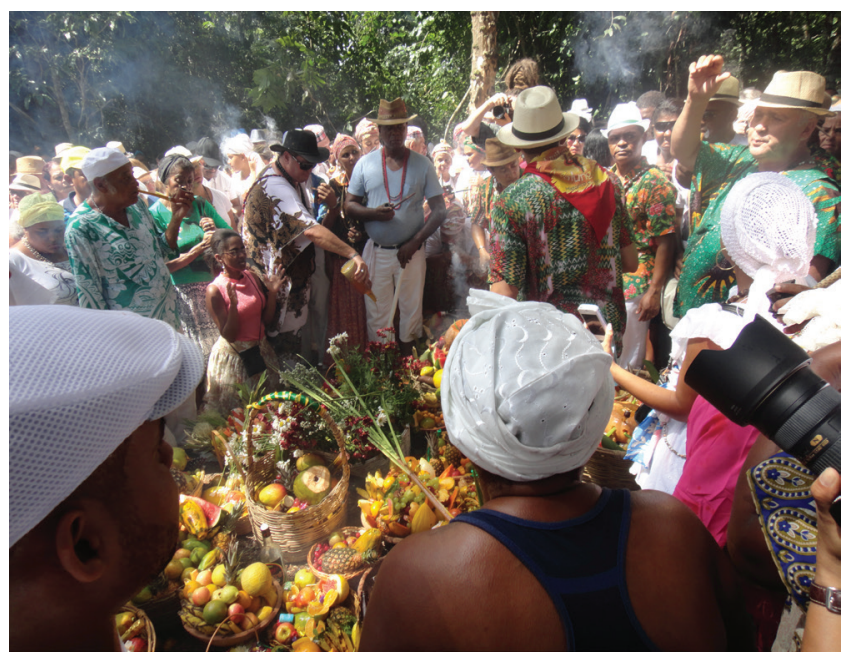

Fonte: Arquivo pessoal de Zuleica Dantas Pereira Campos. 
É promovido pelo Quilombo Cultural Malunguinho (QCM), abalizando o encerramento da Semana Estadual de Vivência e Prática da Cultura AfroPernambucana, estabelecida pela Lei Malunguinho 13.298/07.

Essa lei, de 21 de setembro de 2007, institui a semana de 12 a 18 de setembro como a Semana Estadual da Vivência e Prática da Cultura AfroPernambucana, como reconhecimento do resgate histórico do líder quilombola Malunguinho, morto em combate em 18 de setembro de 1835. Determina que as comemorações poderão ser realizadas por meio de atividades sobre a História da África e Afro-Brasileira; Cultura de resistência do povo negro no Brasil; História das religiões de matriz africanas; História dos Quilombos no Brasil e em Pernambuco; Relações de Gênero e Transgêneros; discriminação e preconceito racial (PERNAMBUCO, 2007).

Como assinala Rodrigues:

É interessante observar que, enquanto o candomblé se apropria da figura histórica de Zumbi dos Palmares, por conta da influência do Movimento Negro na busca das autênticas manifestações culturais africanas, os juremeiros se apropriam de Malunguinho apresentando-o, também, como um personagem de resistência na História do Brasil. Dessa forma, tanto Zumbi como Malunguinho passam a constituir uma mediação entre religiosos e o espaço público (RODRIGUES, 2014, p. 110).

Ainda segundo Rodrigues, existe uma disputa pela legitimidade da Jurema frente ao candomblé, em Recife. Isso fez que os líderes do QCM indicassem o nome de Malunguinho para a Lei. Mesmo pertencendo aos dois tipos de religiosidade, os sujeitos desejam dar uma maior visibilidade para a Jurema por considerarem que sobre ela há um preconceito que envolve seus próprios adeptos. Como a Jurema foi amplamente perseguida nos anos de 1920, 1930 e 1940, em Pernambuco, seu culto foi escondido e sobre ele se abateu uma crença pejorativa de feitiçaria para a sociedade mais ampla (RODRIGUES, 2014, p. 109-110). 
Figura 4 - Imagem do Rei Malunguinho (entidade da Jurema) nas matas do antigo quilombo de Catucá.

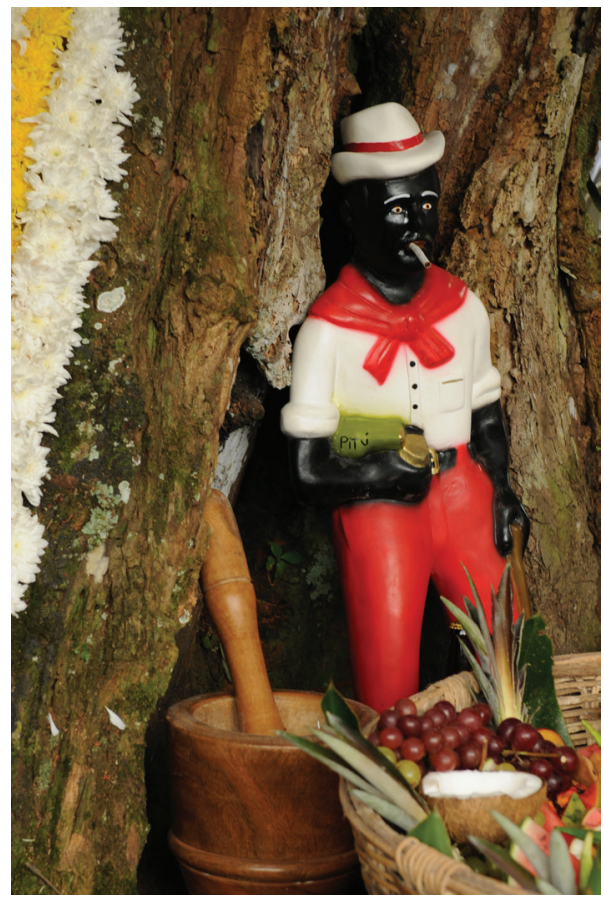

Fonte: Arquivo pessoal de Zuleica Dantas Pereira Campos.

\section{Considerações finais}

Pensamos que a credibilidade da Jurema, junto aos adeptos, sempre foi menor que aquela legada à religião dos Orixás. Se a presença do ameríndio em nossa sociedade foi historicamente colocada em terceiro plano, certamente seu legado religioso também o foi, mesmo porque não foi exclusividade dos praticantes do Catimbó, a perseguição política e policial entre os anos de 1920 e 1940. Aliás, essas religiões historicamente sempre foram perseguidas. O que demarca a perseguição especificamente médica e policial do período é o projeto de medicalização formal e de modernização da sociedade brasileira.

É interessante ressaltar, aqui, o quanto da presença negra existe hoje na prática de jurema. Se formos observar os rituais religiosos, podemos perceber que a inclusão do elemento negro, como também do marginal - legado da umbanda está profundamente marcado. É o caso da forte presença de Exus e pombagiras. 
Dificilmente se encontram praticantes "juremados”, que, por meio do ritual da iniciação implantaram a semente da jurema sob a pele.

A prática da jurema entre os grupos indígenas da região Nordeste faz parte também da sua luta para o reconhecimento frente à sociedade brasileira como categoria social e legitimidade do povo indígena, e assim o direito jurídico a espaços territoriais. Essa identidade não se oficializa por uma herança consanguínea, especialmente entre os grupos da região Nordeste, e sim pela aceitação da pessoa pela comunidade, respeito e conhecimento das práticas rituais. A consanguinidade não é condicional.

O termo de hibridização parece apropriado para conceituar os novos processos culturais que se materializam hoje em um movimento de criatividade individual e coletiva que relativiza a noção de identidade cultural ou étnica: "Entendo por hibridização processos socioculturais em estruturas ou práticas discretas, que existindo de forma separada, se combinam para gerar novas estruturas, objetos e práticas" (CANCLINI, 2000, p. 8).

E é nesse sentido que consideramos o culto da Jurema, seja ele praticado entre grupos indígenas da região Nordeste, seja praticado no espaço urbano da Região Metropolitana do Recife, como um processo contínuo de transformação. Frente a um mundo fluidificado e globalmente conectado, a Jurema reivindica também sua legitimação no campo da sociedade nacional.

Os juremeiros da Região Metropolitana do Recife reivindicam uma ancestralidade indígena. Alguns buscam uma genética indígena por consanguinidade como condição para uma prática legítima. Uma exigência dificilmente comprovada, uma vez que, mesmo entre os grupos indígenas essa religiosidade ficou perdida durante muito tempo. É só a partir do trabalho de resgate e recuperação de elementos culturais entre esses grupos que praticam a Jurema na região do Nordeste do Brasil, que está sendo possível sua reinvenção.

Mesmo se os Juremeiros da cidade do Recife atribuem à pessoa índia uma relação inata a essa religiosidade, considerando-a então como herdeira natural dos segredos da Jurema, não existe aparentemente qualquer contato entre os grupos urbanos e indígenas da região de Pernambuco. Da mesma maneira que procuram distanciar-se das afinidades com os afro-recifenses, os praticantes da Jurema reclamam uma parte dessa ancestralidade africana, como também reclamam uma ancestralidade indígena, mesmo se eles não reivindicam uma identificação com os povos indígenas da região, nem com os afrodescendentes. A trama de fundo desse movimento de atração/repulsão do combate entre negação/afirmação é encenada pelo mundo virtual das representações e tricotada pelas manifestações 
emocionais na busca de um reconhecimento social.

O grupo dos juremeiros do Recife luta pela construção de uma representação à parte, a meio caminho de uma indianidade e de uma africanidade. Se o ritual faz apelo evidente a uma ancestralidade indígena, o movimento que tirou a Jurema de seu quartinho no fundo da casa para colocá-la finalmente no salão foi o culto ao malunguinho, chefe negro quilombola.

\section{Referências}

BRANDÃO, M. C. T. A Localização dos Xangôs na Cidade do Recife. In: CLIO: Revista de Pesquisa Histórica, no. 11, Recife, 1988, p. 117-35.

BRASIL (2005). I Conferência Nacional de Promoção da Igualdade Racial: Brasília, 30 de junho a 2 de julho de 2005. Relatório Final/Secretaria Especial de Políticas de Promoção da Igualdade Racial, Conselho Nacional de Promoção da Igualdade Racial. Brasília: Secretaria Especial de Políticas de Promoção da Igualdade Racial, 2005. Disponível em:

< http://www.seppir.gov.br/central-de-conteudos/publicacoes/pub-seppir/col-pub-seppir> Acesso: 29 mar. 2016.

CANCLINI, Nestor García. La globalización: productora de culturas híbridas?, 2000. Disponível em: <www.hist.puc.cl/iaspm/pdf/Garciacanclini.pdf>. Acesso em: 4 jun. 2009.

CARVAlHO, J. J. A Força da Nostalgia: A Concepção de Tempo Histórico dos Cultos AfroBrasileiros Tradicionais Série Antropológica, $\mathbf{n}^{\mathbf{0}}$. 59, Brasília, 1987 (Mimeo).

CASCUDO, L. C. Notas sobre o Catimbó. Novos Estudos Afro-Brasileiros. Recife: FUNDAJ, Editora Massangana, 1988.

DeleuZE, G.; GUATTARI, F. Mille Plateaux. Paris: Éditions de Minuit, 1980.

FERNANDES, Gonçalves. Xangôs do Nordeste: investigações sobre os cultos negro-fetichistas do Recife. Rio de Janeiro: Civilização Brasileira, 1937.

HABERMAS, Jürgen. Mudança estrutural da esfera pública: investigações sobre uma categoria da sociedade burguesa. São Paulo: Editora Unesp, 2014.

LIVET, P. Les émotion sociales: le visible e l'invisible. In: BERTHOZ, A.; ANDRIEU, B. (Dir.). Le Corps en Acte. Nancy: Presses Universitaires de Nancy, 2010, p. 261-72.

Disponível em: < http://www.psychology.emory.edu/cognition/rochat/lab/sens $\% 20$ de $\% 20$ soi $\% 20$ et $\% 20$ sens\%20de.pdf> Acesso em: 28 mar. 2017.

MAFFESOLI, M. Écosophie: Une écologie pour notre temps. Paris: Cerf, 2017.

MERLEAU-PONTY M. Le visible et l'invisible. Paris: Gallimard, 1964.

MOTTA, R. Religiões Afro-recifenses: ensaio de classificação. In: CAROSO, Carlos; BACELAR, Jeferson (Orgs.). Faces da tradição Afro-brasileira. Rio de Janeiro: Pallas, 1999, p. 17-35.

. Catimbós, Xangôs e Umbandas na Região do Recife. In: MOTTA, R. (Org.). Os Afro-

Brasileiros (Anais do III Congresso Afro-Brasileiro). Recife: Editora Massangana, 1985, p. 109-23. 
. As variedades do espiritismo popular na área do Recife: ensaio de classificação. In: Boletim da cidade do Recife, nº. 2 (nova série), dez. 1977, p. 97-114.

PERNAMBUCO, Lei $\mathrm{n}^{\circ}$. 13.298, de 21 de setembro, de 2007. Disponível em: < http://legis. alepe.pe.gov.br/arquivoTexto.aspx?tiponorma $=1 \&$ numero $=13298 \&$ complemento $=0 \& a n o=20$ $\underline{07 \& \text { tipo }}=>$ Acesso em: 28 mar. 2017.

PINTO, C. M. Saravá Jurema Sagrada: as várias faces de um culto mediúnico, 1995, 210s. (Mestrado Antropologia) Universidade Federal de Pernambuco Recife-PE, 1995.

RIBEIRO, R. Cultos Afro-Brasileiros do Recife: Um Estudo de Ajustamento Social. Recife: IJNPS, 1952.

RODRIGUES, M. G. Da invisibilidade à visibilidade da Jurema: a religião como potencialidade política, 2014, 204s. (Doutorado Antropologia) Universidade Federal de Pernambuco Recife-PE, 2014.

Submetido em: 18-5-2017

Aceito em: 16-4-2018 